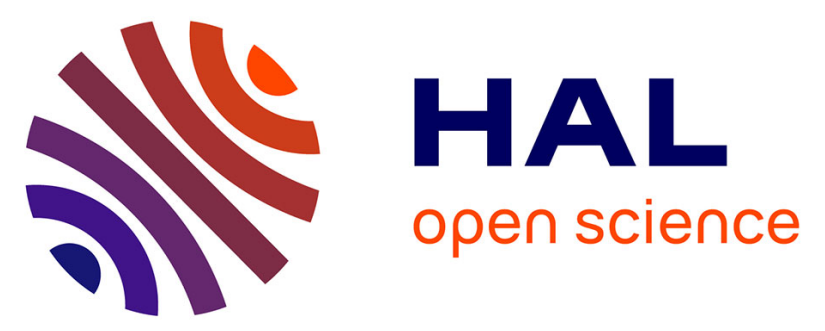

\title{
Singular Extreme Events and Their Attribution to Climate Change: A Climate Service-Centered Analysis
}

Aglaé Jézéquel, Vivian Dépoues, Hélène Guillemot, Amélie Rajaud, Mélodie Trolliet, Mathieu Vrac, Jean-Paul Vanderlinden, Pascal Yiou

\section{To cite this version:}

Aglaé Jézéquel, Vivian Dépoues, Hélène Guillemot, Amélie Rajaud, Mélodie Trolliet, et al.. Singular Extreme Events and Their Attribution to Climate Change: A Climate Service-Centered Analysis. Weather, Climate, and Society, 2020, 12 (1), pp.89-101. 10.1175/WCAS-D-19-0048.1 • hal-02902921

\section{HAL Id: hal-02902921 \\ https://hal.science/hal-02902921}

Submitted on 9 Jun 2021

HAL is a multi-disciplinary open access archive for the deposit and dissemination of scientific research documents, whether they are published or not. The documents may come from teaching and research institutions in France or abroad, or from public or private research centers.
L'archive ouverte pluridisciplinaire HAL, est destinée au dépôt et à la diffusion de documents scientifiques de niveau recherche, publiés ou non, émanant des établissements d'enseignement et de recherche français ou étrangers, des laboratoires publics ou privés. 


\title{
${ }^{\partial}$ Singular Extreme Events and Their Attribution to Climate Change: A Climate Service-Centered Analysis
}

\author{
AglaÉ JézéQuel, ${ }^{\mathrm{a}, \mathrm{b}}$ Vivian Dépoues, ${ }^{\mathrm{c}}$ Hélène Guillemot, ${ }^{\mathrm{d}}$ Amélie Rajaud, ${ }^{\mathrm{e}}$ Mélodie Trolliet, \\ Mathieu VRac, ${ }^{\mathrm{e}}$ JEAN-PAUl VANDERLINDEN, ${ }^{\mathrm{g}}$ AND PASCAL YiOU ${ }^{\mathrm{e}}$ \\ ${ }^{\mathrm{a}}$ LMD/IPSL, Ecole Normale Superieure, PSL Research University, Paris, France \\ ${ }^{\mathrm{b}}$ École des Ponts ParisTech, Cité Descartes, Champs-sur-Marne, France \\ ${ }^{\mathrm{c}}$ I4CE Institute for Climate Economics, Paris, France \\ ${ }^{\mathrm{d}}$ Centre Alexandre Koyré-CNRS, Paris, France \\ ${ }^{\mathrm{e}}$ Laboratoire des Sciences du Climat et de l'Environnement, UMR CEA-CNRS-UVSQ, IPSL and \\ $U$ Paris-Saclay, Gif-sur-Yvette CEDEX, France \\ ${ }^{\mathrm{f}}$ PSL Research University, O.I.E.-Center for Observation, Impacts, Energy, MINES ParisTech, \\ Sophia Antipolis CEDEX, France \\ ${ }^{g}$ CEARC, OVSQ - University Versailles Saint-Quentin-en-Yvelines, Guyancourt, France
}

(Manuscript received 23 April 2019, in final form 9 September 2019)

\begin{abstract}
Extreme event attribution (EEA) proposes scientific diagnostics on whether and how a specific weather event is (or is not) different in the actual world from what it could have been in a world without climate change. This branch of climate science has developed to the point where European institutions are preparing the ground for an operational attribution service. In this context, the goal of this article is to explore a panorama of scientist perspectives on their motivations to undertake EEA studies. To do so, we rely on qualitative semi-structured interviews of climate scientists involved in EEA, on peer-reviewed social and climate literature discussing the usefulness of EEA, and on reports from the EUCLEIA project (European Climate and Weather Events: Interpretation and Attribution), which investigated the possibility of building an EEA service. We propose a classification of EEA's potential uses and users and discuss each of them. We find that, first, there is a plurality of motivations and that individual scientists disagree on which one is most useful. Second, there is a lack of solid, empirical evidence to back up any of these motivations.
\end{abstract}

\section{Introduction}

Extreme event attribution (EEA) is the ensemble of scientific ways to interpret the question "was this event influenced by climate change?" and to answer it (Jézéquel et al. 2018). It proposes scientific diagnostics on whether and how a specific weather event is (or is not) different (e.g., in terms of probability of occurrence, or intensity) in the actual world from what it could have been in a world without climate change (Stott et al. 2016; Otto 2017). EEA is a scientific field whose creation and development have been legitimized through a social utility assumption. When Allen (2003) introduced the

Denotes content that is immediately available upon publication as open access.

Corresponding author: Aglaé Jézéquel, aglae.jezequel@lmd.ens.fr concept of event attribution, he stated a clear motivation: to provide the basis for science-based liability. Based on EEA results, individuals faced with attributable losses could sue polluters to compensate their losses. Allen and Lord (2004) develop this argument further, asking "who will pay for the damaging consequences of climate change?" following the first event attribution of summer 2003 European heatwave by Stott et al. (2004). With the development of attribution science, scientists started to advance other social reasons to motivate their research. For example, Pall et al. (2011) state that "[their] approach could prove a useful tool for evidence-based climate change adaptation policy" (p. 385). In doing so, they shifted the potential use for EEA from liability to adaptation. It is noteworthy that there is a lack of evidence to support any of the motivations advanced in the articles cited above. Since then, a number of studies have explored the different potential uses and users of EEA 
(Stott et al. 2013; Hulme 2014; Sippel et al. 2015; Schwab et al. 2017).

As a testimony to this strong belief in the social utility of EEA, there is already momentum at the European level to create an extreme event attribution climate service. The EUCLEIA (European Climate and Weather Events: Interpretation and Attribution) project, which ran between 2014 and 2016, investigated the possibility of building such a service. Its successor, EUPHEME (European Prototype Demonstrator for the Harmonisation and Evaluation of Methodologies for Attribution of Extreme Weather Events), funded by the European Research Area for Climate Services (ERA4CS) consortium, aims at delivering a prototype of such a service. In parallel, the European-funded Copernicus Climate Change Service (C3S) prepares the ground for an operational attribution service, with the release of a proof of concept in January 2019 (https://climate.copernicus.eu/ prior-information-notice-c3s62-proof-concept-extremeevents-and-attribution-service).

Although EEA has been developed with users in mind, its development has been driven by scientists, on the supply side, rather than "driven by users" on the demand side (https://cordis.europa.eu/project/rcn/200835/ factsheet/en). Because of this push by the supply side, there is a need for promoters of this new climate service to clarify who could use it and for what benefits.

In this context, the goal of this article is to explore a panorama of scientist perspectives on their motivations to undertake EEA studies. To do so, we rely on three sources of information, which allow us to update and go further than previous studies (Stott et al. 2013; Hulme 2014): a literature review, the EUCLEIA reports, and interviews of climate scientists. These three sources are detailed in section 2. The potential benefits of EEA correspond to different users, with sometimes converging interests. A classification scheme emerged from the analysis of our datasets and allowed for the organization of our results presented in section 3. Sections 4 and 5 detail the results for the different types of EEA uses identified in our classification scheme. We specifically aim at identifying the added value of EEA for each of the identified benefits, compared to more general statements on the evolution of extreme events with climate change. To conclude, we discuss in section 6 what the results of our analysis entail for the implementation of a climate service.

\section{Datasets}

To analyze the motivations of climate scientists to engage in EEA and how those motivations meet the social demand, we triangulated data from three sources: peer-reviewed social and climate literature discussing the usefulness of EEA, the EUCLEIA reports, and interviews of climate scientists involved in EEA.

The literature review was conducted on articles published before the end of 2018 through a combined search on Google Scholar for the keyword "extreme event attribution" and other keywords (stakeholders, adaptation, litigation, liability, loss and damage, insurance, and awareness raising). We only kept the articles that were effectively discussing EEA. We completed this list by systematically checking the reference lists of the selected articles for other relevant articles. Some of the references used in this article do not discuss EEA but the relevance of climate and extreme event science for adaptation, awareness raising, and climate services, as they give important context.

EUCLEIA reports, although most of which have not (yet) led to peer-reviewed articles, contain valuable information, as Work Package (WP) 4 of EUCLEIA aimed at "assessing detection and attribution through general public and stakeholder analysis." These reports contain the results of studies regarding the interest of insurers, regional decision-makers, and the general public in a potential EEA service. They are accessible online on the EUCLEIA website (https://eucleia.eu/ reports/).

Then, we analyzed the answers of two corpora of semi-structured interviews with EEA scientists. The first corpus of 10 interviews was conducted in April 2014 in the context of the EUCLEIA project to evaluate the feasibility of an EEA climate service. The second corpus of 9 interviews conducted between June 2016 and January 2017 aimed at understanding the motivations behind the undertaking of EEA and what scientific and social use scientists see for EEA. Hereafter, we name these corpora the EUCLEIA corpus and the A2C2 (Atmospheric Flow Analogue and Climate Change; https://a2c2.lsce.ipsl.fr/) corpus, after the names of the projects that funded them. These two corpora have been used for Jézéquel et al.'s (2018) analysis of the different ways to frame EEA. The A2C corpus was also used by Jézéquel et al. (2019) to specifically explore the potential use of EEA for loss and damage. The interview grids are available in the supplementary material of Jézéquel et al. (2018). Given the speed of development of both EEA and of the EEA climate service, the interviews depict a state of the EEA community that may have evolved. However, they present a state of the EEA community as some of them were already thinking of implementing a climate service. They hence contain valuable information on the motivations of scientists to do EEA. 


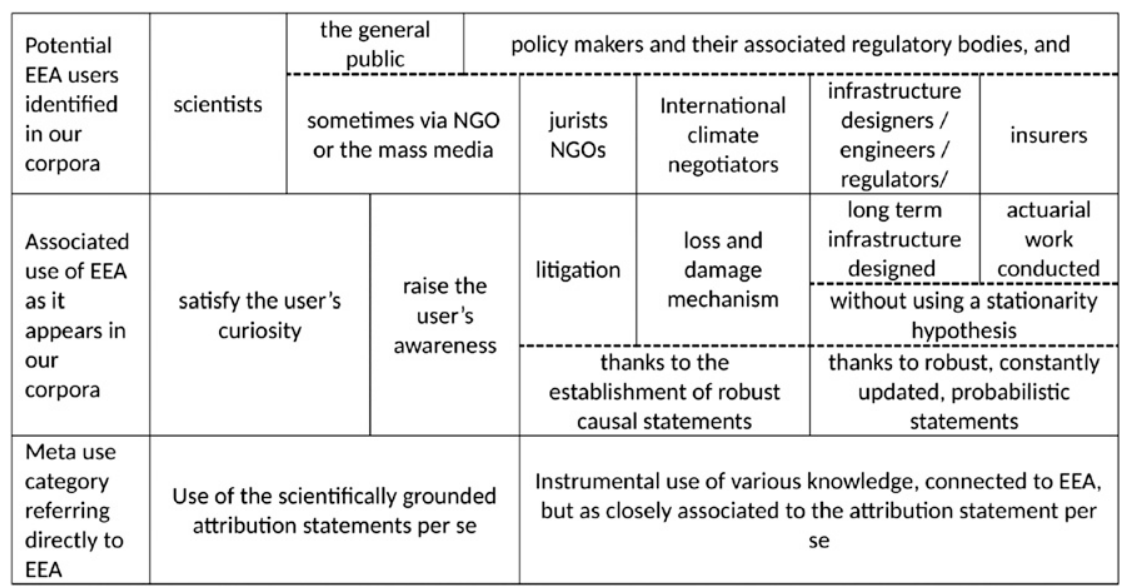

FIG. 1. Mapping potential users and uses of EEA. There are potential benefits associated with the mere knowledge produced by EEA (such as satisfied curiosity or increased awareness). There are potential benefits associated with the instrumental use of this knowledge (such as using the associated causal statements for litigation or loss and damage, or such as using more accurate probabilistic statements for actuarial practices or infrastructures).

\section{An emerging classification scheme}

Stott et al. (2013) present reasons to pursue EEA by groups of stakeholders. Hulme (2014) discusses the motivations for scientists to engage in EEA by types of uses. To build a classification for this article, we started by identifying both the potential users (first line of Fig. 1), and the associated uses (second line of Fig. 1). This distinction was motivated by overlapping of both categories, as can be seen in Fig. 1. The identification of uses and users is based on our three datasets. We note that there may be blind spots in these datasets regarding potential users, which may derive on our more general analysis of EEA usefulness. Our analysis, through the lenses of EEA's potential uses, led us to the identification of two broad categories (third line of Fig. 1). One category, where the attribution statement would be of direct relevance through the increase in knowledge that it represents, is connected directly to either the satisfaction of curiosity or the associated increase awareness. The other category is connected to more instrumental use of EEA through the better identification of either causal chains leading to extreme events or through an improved assessment of probabilities of extreme events in a changing climate.

For each of these uses it is possible to further analyze how they may play out. This is the purpose of the following sections that are organized according to the classification scheme that is presented in Fig. 1. Each subsection starts by presenting what the literature says about one specific use of EEA, then what the interviewees said about it, and, if relevant, the conclusions of the EUCLEIA reports. We conclude each subsection with a discussion on the value of EEA for the identified use.

\section{Using scientifically grounded attribution statements per se}

\section{a. Using EEA to answer curiosity}

Hulme (2014) advances the motivation of scientific curiosity, as attribution of individual events "piques the scientific mind" (p. 3). It pushes the boundaries of climate models by asking them different questions, and encourages scientists to test original configurations of their models (Massey et al. 2015). Stott et al. (2013) highlight the challenges in understanding and modeling extreme events and how they are affected by anthropogenic climate change. The momentum related to EEA has led to more research on these topics, and hence participated in the improvement of extreme event science.

The scientific motivation to pursue EEA is mentioned by almost all the scientists interviewed in the $\mathrm{A} 2 \mathrm{C} 2$ corpus, and it came up three times in the EUCLEIA corpus. As the EUCLEIA corpus explored the scientists' perspectives on the building of a climate service, aimed at nonscientist stakeholders, the lack of reference to a scientifically grounded motivation is not surprising. However, even in the $\mathrm{A} 2 \mathrm{C} 2$ corpus, this motivation is not presented as the main motivation-both in terms of time spent on it during the interview and in scientists' evaluation of which EEA uses were most importantstated by scientists in the interviews.

In the interviews, we found a discrepancy in the views of EEA as a scientific object. From two different 
interviews we get both "from a scientific perspective it is maybe not quite as useful" and "from a scientific point of view, it's extremely interesting." On the one hand, a few interviewees raised concerns about the relevance of EEA as a research question. For example, one of the interviewees fears that EEA is "a little bit like ambulance chasing" and "that is what paparazzi do." If EEA becomes more of a climate service and more of an engineer type of work in the future, "then at that stage, the scientific value of undertaking this kind of research becomes lower." It is interesting that those worries exist within a pool of climate scientists who have participated in EEA. Indeed, similar concerns have also been expressed by climate scientists in general, outside of the EEA community. Bray and von Storch's (2016) survey shows that part of the climate science community is not even convinced it is possible to attribute an event to climate change [see Fig. 77 of Bray and von Storch (2016)] and is not convinced of the robustness of existing EEA results (Fig. 73).

On the other hand, we found arguments to defend the scientific potential of EEA in the interviews. According to the interviews, EEA interests scientists for three reasons. First, it is a "difficult" and "challenging" problem. Second, it presents opportunities for the development of new methods and scientific knowledge. Third, EEA tests the ability of climate models and tools in front of a complex problem: "it is useful [...] for generating understanding of the tools that we have at hand" (see also Stott et al. 2013). From this standpoint, the limitations of EEA are informative in themselves.

The points of view regarding the scientific interest of EEA differ. It is undeniable that the momentum created around this research question has led to improvements in statistical and physical tools used in climate science, as well as better understanding of the physical processes leading to specific extreme events. The diversity of EEA approaches is an asset to develop the science of extreme events in several directions. An interesting characteristic of EEA is that it links weather, and meteorology, to climate science. Keeping in mind that a lot of climate scientists have been trained in meteorology, this could partly explain the appeal of EEA for them, as a way to relate their current scientific practices with their backgrounds. Finally, curiosity is of course not confined to the scientific community and around half of the interviewees consider that there is an interest in EEA from the general public ensuing from "the satisfaction of understanding something."

\section{b. Using EEA knowledge as an awareness raising device}

Hulme (2014) argues that frustration regarding the invisibility of climate change (Rudiak-Gould 2013) is another reason that pushes scientists toward EEA. Stott et al. (2013) recommend rapid attribution in the wake of extreme events to inform the general public (see also Stott and Walton 2013). Bray and von Storch (2016) reveal mixed feeling in the pool of scientists they surveyed regarding the ability of EEA results to make climate change visible and convince citizens of the reality of climate change. According to the two corpora of interviews, this awareness raising seems to have two potential end users: the general public and decision-makers, both mainly through the media, who are intermediary recipients. NGOs are other potential intermediary recipients who are almost never discussed either in the interviews or in the literature.

\section{1) For THE GENERAL PUBLIC}

Awareness raising is the motivation mentioned the most in the interviews, probably because it is the only one for which many of the interviewees have been responding to an explicit demand from journalists. This does not mean, however, that all interviewees find the media to be the most relevant users (e.g., "the media and all that, that's not very interesting to me").

There are many questions surrounding media interest in EEA. There is no denying that it exists, since the majority of the interviewees mentioned the media as a user they interact with more or less frequently. It is trickier to decipher which media circulate or might circulate in the future EEA results. For example, regional German and French media outlets cover extreme events like rainfall or storms without linking them to climate change, in contrast to national newspapers, which are more interested in EEA (EUCLEIA 4.4 report; Vanderlinden et al. 2016). This distinction between coverage of extreme events and coverage of their attribution is also brought up in the $\mathrm{A} 2 \mathrm{C} 2$ corpus. An interviewee highlights that the climate change angle is not always preferred by the media covering extreme events: "Most of the stories that get written just report on the event and they don't say anything about climate change or how this particular event may have been worse because of the human activities. [...] But there is a number of reports where climate change does get some mention."

Another question is how much EEA has gained, and is gaining ground in diverse types of media, including social media, with the increase in EEA studies (even since the EUCLEIA reports). While journalists demonstrate a high level of interest in EEA studies, as proven by the numerous solicitations that our panel of interviewees received following a number of extreme events, it does not automatically translate into as large an allocated space in the final publication as the scientists could expect: 
other topics, such as sports, politics, economy, or entertainment, compete with and may overshadow climate change news. The efficiency of EEA stories (should they be published) in actually changing the opinion of individuals is even more complicated to evaluate.

Most of the interviewees perceive EEA as a useful communication tool. It would help people to understand the links between climate and weather. As a different way to communicate climate change, implicitly or explicitly compared to more traditional ways to explain climate change, like the IPCC (Intergovernmental Panel on Climate Change) reports, EEA could make climate change visible, and unveil its impacts. People worry more about extreme events (e.g., $5^{\circ} \mathrm{C}$ temperature anomalies over France in summer 2003) than about how averaged variables evolve, because the range of averaged variations is deemed small (e.g., $\sim 0.5^{\circ} \mathrm{C}$ in 100 years for planetary mean temperature). EEA could hence make people realize the seriousness of climate change through its impacts on extremes. Another argument for EEA as a tool of communication is that it would be a way to link climate change to people's experience, rather than to abstract scientific results. At this point, we find it important to highlight that there are many approaches to EEA, one of which, called the storyline approach, has been precisely developed with this goal in mind (Trenberth et al. 2015). In the words of Shepherd (2016), it "examines the role of the various factors contributing to the event as it unfolded, including the anomalous aspects of natural variability, and answers the question deterministically" (p.1). This approach of EEA is supposed to enhance episodic memory, the ability to comprehend future risk based on previous experience (Shepherd et al. 2018; Shepherd 2019). This idea is consistent with Schacter et al.'s (2007) argument that the memory of past events plays a role in our ability to imagine future events, and hence to anticipate them. Two interviewees also bring up the potential of EEA to change the opinion of climate contrarians. Finally, one interviewee remarks that even without EEA, people make their own attribution statements: "people make attribution statements without scientific evidence if we do not provide scientific evidence. I think overall it makes more sense to do it with the scientific evidence we have" (see also Leiserowitz et al. 2012).

One of the major difficulties to communicate EEA results lies in the gap between the present form of EEA results and the simplicity of the answers the media and the general public want. It is identified by a few interviewees: for example, "I am under the impression that quantifying the change in probability of occurrence is not their first interest, what concerns them the most is whether there is an anthropogenic contribution or not."
This difficulty was also raised in the EUCLEIA corpus to answer the question "What are the arguments you would expect from someone believing that extreme event attribution services are not needed or not desirable?" [see the interview grids in the supplemental material in Jézéquel et al. (2018)]. For example, "It may be almost impossible to get this message across, because we're not having a yes or no message, a zero or one message, but we're having something in between which is indeed hard to get across to people." This also ties back with the choice of approach to EEA, which will also influence the type of results. For example, the most popular approach to EEA, the risk-based approach, typically provides probability ratios, while the storyline approach underlines how and why the physical processes leading to an extreme event can be affected by anthropogenic climate change [see Shepherd (2016), National Academies of Sciences, Engineering, and Medicine (2016), Lloyd and Oreskes (2018), and Jézéquel et al. (2018) for more information on the different EEA approaches]. All these points should be taken into account when designing an EEA approach to use for awareness raising. Confronting people with different ways to present EEA information through in-depth interviews and/or a survey would be a way to move forward on this topic. For example, Knoblauch et al. (2018) conducted a survey to test how people reacted to different ways to communicate risks of induced seismicity due to new technologies. They presented their sample with three different formats of written risk communication. They found that the respondents preferred having both qualitative and quantitative information, rather than only qualitative information.

Last, it is important to be realistic regarding the potential for EEA to raise awareness for the general public. Many other dimensions factor in the debate. For instance, in the United States Marquart-Pyatt et al. (2014) have shown the perception of climate change is driven by political orientation, and that the influence of climate extremes is not discernible (at least at the time of their study). Konisky et al. (2016) find a "modest, but discernible" effect of extreme events on climate change awareness, but only for recent events, hinting at a shortterm phenomenon. Bohr (2017) finds that temperature anomalies exacerbate political polarization on climate change, rather than change the initial opinion of the affected people. Hamilton et al. (2016) find similar results for floods. Marlon et al. (2019) argue that it is because of the subjectivity of the general public perception of climate change that experts and scientists need to step up and interpret weather events in regards of climate change. Events alone will not be sufficient to make climate change visible, although commented events could. 


\section{2) FOR POLICY-MAKERS}

Other potential targets for awareness raising through EEA that we found in all our datasets are policy-makers, especially those dealing with adaptation to climate change. For example, one interviewee from the EUCLEIA corpus states that "it helps to have a tangible event," which shows that "it's already occurring." Two interviewees from the $\mathrm{A} 2 \mathrm{C} 2$ corpus also present EEA results as a mean to increase the acceptability of possibly unpopular adaptation decisions: "the expectation of the customers is that the people that they deal with understand why they made that choice, and don't question." They see EEA as a tool to justify decision-makers' actions in the eyes of their voters. This point is also mentioned in Sippel et al. (2015). One of their interviewees finds the focus of EEA on the current state of the climate valuable as it "would unambiguously highlight the relevance for addressing and reducing public health related risks now, not only in a somewhat distant future."

The connection between information for decisionmakers to trigger a change of practice and awareness raising for said decision-makers is not restricted to adaptation decision-makers. Three interviewees (two from the EUCLEIA corpus, one from the A2C2 corpus) expressed the view that EEA information could help to show the impacts of climate change and push policy-makers to adopt ambitious emissions targets, in order to avoid further impacts: e.g., "we need to quantify the risk as well so that we can make informed judgments about how much money we should spend in order to mitigate those risks." This reasoning of political pressure on governments is consistent with the results of Bray and von Storch's (2016) survey of climate scientists, revealing that most scientists agree that successful EEA would help to demonstrate the urgency of reducing greenhouse gases (see Fig. 75 of Bray and von Storch 2016). They are even more convinced of this than of EEA's potential to support the design of adaptation strategies, although they are generally convinced of the latter point (see Figs. 76 and 78 of Bray and von Storch 2016). Whether EEA information could be effective in this case has yet to be proven.

\section{Instrumental use of EEA-related knowledge}

Another hope expressed by EEA scientists is that their results could be useful to create new tools for different stakeholders so that society could better take climate change into account. We identified four potential uses: two associated with obtaining more credible causal statements, namely litigation and loss and damage, and two associated with obtaining more robust probabilistic statements, namely insurance and infrastructure design.

\section{a. Improved causal statements for litigation and loss and damage}

The potential to establish climate change liability was the initial motivation for EEA. Stott et al. (2013) propose this motivation relying on arguments advanced by Allen et al. (2007), who defend an operational attribution system, which could simplify the judge's task regarding an otherwise complex question. Hulme (2014) expresses concerns regarding the robustness of attribution statements and whether methodology and modeldependent results could "hold sway in courts." This motivation is part of the larger context of emerging climate litigation (Adam 2011; Grossman 2003).

Climate change litigation is steadily growing worldwide [see Fig. 6 of Nachmany et al. (2017)]. As of 14 January 2018, the U.S. Climate Change Litigation Database includes 977 cases, and the non-U.S. Climate Change Litigation Database includes 275 cases (http:// climatecasechart.com/about/). Climate change litigation is a growing, but still new legal topic, which still has a lot of challenges to tackle (Adam 2011; Thornton and Covington 2016; Torre-Schaub 2018). The "lawsuits dealing with personal property damage or injury caused by climate change-related events," for which EEA could be relevant, represent only a minority of cases (Nachmany et al. 2017). This does not mean that this type of cases has no potential to develop in the next few years, especially with the advances of science, and its ability to link damages to climate change (Marjanac and Patton 2018; Nachmany and Setzer 2018).

Five interviewees brought up liability as a potential motivation for EEA. They think that EEA may play a role in courts, although they are aware that it is not yet the case. Two of them hint at a rise in interest from the legal community based on exchanges with stakeholders. However, one interviewee points out that a case can be concluded without EEA information: "there have been other circumstances when the case has been concluded, without getting to that point."1 Another raises concerns regarding the current lack of robustness of EEA: "it needs to be handled with great care in that kind of area, because it really has a long way to go before it's sufficiently robust to provide sufficiently clear answers" [similar to Hulme's (2014) point].

\footnotetext{
${ }^{1} \mathrm{~A}$ famous example of climate change legal case where the court condemned the accused party for contributing to dangerous climate change is the Urgenda case of the Urgenda Foundation against the Dutch government.
} 
Recently, two articles have discussed the use of EEA for litigation (Marjanac and Patton 2018; Lusk 2017) in common law jurisdictions. They come to opposite conclusions. On the one hand, Lusk (2017) argues that even if EEA solved the attribution problem it would not be sufficient to solve legal liability. He bases his argumentation on the Comer v. Murphy Oil case (2012), in which a group of Mississippi homeowners sued a group of oil and energy companies for damages related to Hurricane Katrina in 2005. The court did recognize the role of anthropogenic emissions in Katrina, without the help of EEA, although there is very limited scientific material to support this statement. However, "the court found the plaintiffs did not have a standing" for three reasons: 1) the untraceability of greenhouse gases (the mixing of gases in the atmosphere makes it impossible to relate the damages caused by Katrina to the specific emissions of the defendants), 2) justiciability (the court found the topic to be political, meaning it should be addressed by legislative rather than legal action), and 3) preemption (the court could not punish defendants for "actions at one point formally encouraged by other branches of the government").

On the other hand, Marjanac and Patton (2018) argue that EEA could be an essential step in the causal chain for climate change litigation. They claim that the type of scientific evidence from EEA could be accepted in courts by drawing analogy with similar types of evidence of causation, like results from epidemiology, which have been used in health-related cases. They show that both the United States and the United Kingdom laws have developed ways to "find exceptions to the traditional deterministic 'but for' test for causation in certain circumstances." The "but for" test would correspond to necessary causation, for which the damages suffered by the plaintiffs would not have occurred but for the defendants' actions. Marjanac and Patton (2018) remark that three case studies from the BAMS report on 2016 extreme events pass the "but for" test (Knutson et al. 2018; Walsh et al. 2018; Imada et al. 2018). However, most EEA studies do not find a null probability of occurrence of the event in a world without climate change. ${ }^{2}$ Marjanac and Patton (2018) hence discuss the possibility for climate change litigation for this majority of cases.

\footnotetext{
${ }^{2}$ Marjanac and Patton (2018) only discuss the risk-based approach to EEA that compares the probability of the event in the actual world with climate change to its probability in a counterfactual world, without anthropogenic climate change. A point could be made that the storyline approach could be used as a "but for" test, since it precisely shows how the event or its impacts would have been different, but for climate change. It will be interesting to see what kind of evidence will be used in potential future cases.
}

For this motivation, if the parallel with epidemiology is to be followed, the focus of EEA on specific events with the calculation of risk ratios similar to those being used in health-related cases (although not always correctly interpreted; McIvor 2013) presents an important added value. However, Marjanac and Patton (2018) base a large part of their arguments on a statement that advances in EEA will result in advances in foreseeability. In courts, proving foreseeability means that the defendants had access to information showing that climate change modified the risk of the event that engendered damages. If they did not take appropriate action to respond to this change of risk, leading to damages experienced by the plaintiffs, it could make a case for negligence claims. Since EEA analyzes the influence of climate change on extreme events after they happened, it puts more weight on ex-post science than on foreseeability. It uses the available science just after the event happened to calculate a risk ratio or a fraction of attributable risk. Observation datasets, models, and tools are constantly improving. Hence, EEA results could, by definition, not have been available to the defendant prior to the event that caused the damage. This does not mean that climate science cannot provide a basis for negligence claims, but this implies that EEA would have to evolve from its ex-post perspective to be more relevant for this specific purpose. To go in this direction, there are already techniques to calculate risk ratios for plausible events (e.g., temperature beyond a certain threshold) that have not happened yet (Christidis et al. 2015).

More generally, there are still many hurdles on the way to climate change litigation. At this point, it is not clear if EEA could (and will) be used or not. Exchanges between legal experts and climate scientists will be necessary to define which type of scientifically based evidence could stand in courts. The existing studies focus on the U.S. and U.K. systems. There is a need to expand this research to other countries with different judicial systems.

The use of EEA for climate liability also connects to the potential use of EEA for loss and damage in the context of the UNFCCC (United Nations Framework Convention on Climate Change) and through it, to international liability. The Paris agreement recognizes "the importance of averting, minimizing and addressing loss and damage associated with the adverse effects of climate change, including extreme weather events and slow onset events." It hence poses the question of the link between the adverse effects of extreme weather events and climate change. While a number of papers highlight the importance of EEA for loss and damage (James et al. 2014; Thompson and Otto 2015; Mace and Verheyen 2016; Verchick 2018), others are more cautionary (Hulme et al. 2011; Wallimann-Helmer 2015; Surminski and Lopez 2015; 
Boran and Heath 2016; Huggel et al. 2016; Lusk 2017; Roberts and Pelling 2018). Parker et al. (2017), James et al. (2019), and Jézéquel et al. (2019) discuss the potential use of EEA for loss and damage based on interviews with stakeholders involved in both fields. We chose not to discuss loss and damage at length here as we considered that James et al. (2019) and Jézéquel et al. (2019) have already covered the topic extensively. They find that the inclusion of EEA results in a mechanism to address loss and damage driven by climate negotiations is unlikely, but point out that it could be useful through other channels.

\section{b. Probability distributions more attuned to the needs the insurance sector or for adaptation planning}

\section{1) FOR THE INSURANCE SECTOR}

Stott et al. (2013) make the point that EEA shows that insurers cannot base their risk calculation on the hypothesis that the climate is stationary (Phelan 2011). EEA case studies indeed give concrete examples that the probability of extreme events has changed due to anthropogenic emissions. This has been identified as a sector of application by a part of the interviewees, mostly from the EUCLEIA corpus. This asymmetrical distribution of answers between the corpora might be related to the fact that insurers were identified as potential stakeholders in the EUCLEIA project. This sector of application was discussed in general assemblies and workshops where the EUCLEIA members were present. It is noteworthy that one interviewee doubts the potential interest of insurers in EEA: "the insurance companies I'm aware of might not be willing now to look at such services."

A study of insurers' interest in EEA was conducted within the EUCLEIA project (EUCLEIA 4.3 report; von Storch et al. 2016). In-depth interviews with German and French insurers and reinsurers were conducted and analyzed. Interviews showed a general interest of the insurers in EEA. However, this interest is nuanced by a number of " 'but's like that EEA does not provide an added value to the existing information, other components of risk are more important, or that it is not applicable in existing business processes" such as actuarial practices and, yet less clearly so, strategic planning. Another conclusion was that "despite the fact that most of the interviewees were certain that EEA is relevant, no one was convinced that the added value of EEA is currently large enough to pay for it." The European insurance sector operates in a quite constraining regulatory environment, which may curtail the use of innovative methods and approach as they are developed.
In the case of the insurance sector, it is clear that the change of probabilities of meteorological hazard matters (e.g., Reguly 2013; Warner et al. 2013). What is less clear is whether EEA is the most relevant way to address the insurers' needs. What seems most relevant for the insurance sector, while being the by-product of some studies, would be the calculation of the current probability of occurrence of the event. The proof of causation (or the calculation of the probability of occurrence of the event in a world without climate change), seems not especially relevant in the insurance context. "[One interviewee thinks] that insurers don't care at all about the causal explanation. [...] what really matter is the risk, and its evolution" (von Storch et al. 2016). Another issue is that EEA is tailored to very specific types of events, such as the exceedance over a given threshold in a given region, for a given duration, rather than general classes of events like storms, heatwaves, or floods. Last, insurance is based on risks, not only on probabilities of hazards, which also rely on an evaluation of exposure and vulnerability (Sillmann et al. 2018).

\section{2) FOR ADAPTATION PLANNING}

Beyond the insurance sector, better ascertained probabilities may be useful within the context of adaptation planning. The perspectives regarding the potential use of EEA for adaptation in the literature diverge. For example, the stakeholders interviewed in Sippel et al. (2015) adopt a variety of viewpoints on the potential of EEA for guiding the allocation of adaptation funds. Some of them think it will be useful, while others expect the process to be piloted by political moves rather than scientific evidence.

On the one hand, Stott et al. (2013) make two points. First, they state that extreme events can be "harbinger[s] of the future." Attribution statements regarding the evolution of their probability could help decisionmakers to allocate funds for adaptation (see also Hoegh-Guldberg et al. 2011). Second, Stott et al. (2013) are concerned by possible cases of misattribution, which "could lead to poor adaptation decisions" (Stott and Walton 2013), by adapting to events that will become rarer in the future (like cold spells). This conception of the use of EEA falls within a more general vision that extremes can be "pacemakers of adaptation"3 (Travis 2014; Moser and Boykoff 2013; Füssel 2007). The added information provided by EEA in case of events becoming

\footnotetext{
${ }^{3}$ Extremes could be seen as "pacemakers of adaptation" as their impacts reveal vulnerabilities faster than a change in global mean would. Travis (2014) has shown that adaptation in response to extreme events is not systematic, and not necessarily significant.
} 
less likely because of climate could help to avoid some of the maladaptation practices described by Travis (2014). This benefit should however be nuanced as Travis (2014) also shows that the role of extreme events in triggering adaptation is still ambiguous, and highly dependent on the event and on the social and political environment in which it occurs: "the net effect of extremes on larger policy structures remains ambiguous in the literature, with the hint that even a strong signal does not necessarily ratchet policy adaptation" (p. 37).

On the other hand, Hulme's (2014) main point of contention is that this reasoning is based on the assumption that adaptation should be based on optimal decisionmaking. ${ }^{4}$ Given the nature of climate change and the existing uncertainties on both climate variability and how it is affected by climate change, authors have been arguing for an approach of adaptation focused on robust decision-making 5 (Dessai and Hulme 2004; Dessai et al. 2009; Weaver et al. 2013). Hulme also argues that the allocation of adaptation funding should be based on vulnerability to extreme weather events, rather than attributability (Hulme et al. 2011; Hulme 2014). Another argument against the use of EEA for adaptation has been advanced by (Thompson and Otto 2015; Lusk 2017), who argue that since EEA adopts an ex-post point of view on extreme events, it is not suited for adaptation, which should rather be forward looking.

EUCLEIA dedicated a work task to "the understanding of user needs and the value of extreme event attribution for regional stakeholders." "Most stakeholders found that [EEA] would not change their own motivation or way of taking action. They told to be rather in need of information about vulnerability, potential impacts and promising adaptation options; such information was not perceived to be enhanced by EEA results" (EUCLEIA 4.2 report; von Storch et al. 2015). The group of stakeholders interviewed for EUCLEIA rather found that EEA had potential for awareness raising of climate change (see section $4 \mathrm{~b}$ ). Another important result from EUCLEIA was that: "the assumption that EEA facilitates a more effective resource distribution, planning

\footnotetext{
${ }^{4}$ Optimal decision-making relies on scientific evidence to choose the decision that will minimize the losses. It is hence based on a predict then act decision framework. Within the context of EEA this would mean calibrating adaptation measures based on the specific characteristics of attributed events.

${ }^{5}$ Robust-decision-making "seek[s] to identify policy vulnerabilities under deep uncertainty about the future and propose strategies for minimizing regret in the event of broken assumptions" (Weaver et al. 2013, p. 39). It is hence based on an exploratory (or heuristic) decision framework. In that case EEA can only provide plausible instances but not represent the full range of possible variability.
}

and implementation of climate adaptation could not be confirmed" (EUCLEIA 4.2 report; von Storch et al. 2015). These results were also the object of an article (Schwab et al. 2017).

It is hard to find an argument specific to EEA-which would not apply more generally to the science of understanding the influence of climate change on extreme events-in the three datasets to explain why and how EEA could help adaptation stakeholders. Nevertheless, the idea that EEA could inform and motivate adaptation is discussed by the majority of interviewees, and more specifically in the EUCLEIA corpus. Only one interviewee explicitly states that he does not believe EEA could be useful in the context of adaptation. Two interviewees highlight that climate change-related risks are "felt most strongly through impacts of extremes." Three others argue that understanding that extreme events are already changing because of climate change is a signal for the future of extreme events. These arguments can be applied to EEA, but they relate more generally to the development of science studying extreme events in the context of climate change.

\section{Discussion}

What emerges from this panorama of scientist perspectives on their motivations to undertake EEA studies is that, first, there is a plurality of motivations and that individual scientists disagree on which one is most useful. We have identified four main motivations: to satisfy the user's curiosity, to raise the user's awareness, to establish robust causal statements either for litigation or loss and damage, and to provide robust probabilistic statements to users for infrastructure design or actuarial work. Second, there is a lack of solid, empirical evidence to back up any of these motivations. In fact, the few empirical studies that have been conducted (the EUCLEIA reports; Schwab et al. 2017; Jézéquel et al. 2019) rather tend to find inconclusive results regarding the use of EEA for nonscientific stakeholders. This does not mean that EEA cannot be useful, but simply that its usefulness is not straightforward, especially when it comes to social needs, and ought to be demonstrated for specific groups of stakeholders, which has not been done yet. Such types of studies should be easier to do now that EEA has developed, and that there are a number of existing methodologies and approaches, which could be presented to stakeholders to test their relevance for different uses.

EUCLEIA, EUPHEME, and the recent C3S proof of concept all show that there is an institutional push for an extreme event attribution service at the European level. The objective of the potential C3S attribution service 
would be to "address the ever-growing demand from a wide range of stakeholders, including media and legal representatives, on understanding the relationship between recent extreme weather events and anthropogenic climate change." This is in line with the ERA4CS vision of climate services as "driven by users' demands." However, it is also in contradiction with the results presented in this article.

This apparent discrepancy poses a number of fundamental questions both for this specific service and for the construction of European climate services in general. First, it questions the definition of climate services, and its meaning for different stakeholders. In its Global Framework for Climate Services (GFCS), the World Meteorological Organization (WMO) proposes the following definition: "Climate services provide climate information in a way that assists decision making by individuals and organizations. Such services require appropriate engagement along with an effective access mechanism and must respond to user needs." This complies with the idea that interactions with users during the construction of a climate service are essential to build effective climate services (Vaughan and Dessai 2014; Hewitt et al. 2012). In this line, both EUCLEIA and EUPHEME have devoted a work package to the link with potential users. The results of EUCLEIA have been discussed in this article. EUPHEME's working group 1 aims at "establish[ing] a dialogue between users and scientists to develop a clear common understanding of event attribution and its uses including the full range of methodological uncertainties and potential implications for decision making." This suggests that the result (an active co-constructed service) is not yet guaranteed at the beginning of a climate service project.

This last observation asks the question of what should be done with inconclusive results on the co-construction side, similar to what happened in EUCLEIA. It is noteworthy that a few of our interviewees are concerned by a potential lack of users; for example, "I do not know if [an attribution service] would be really useful" or "I am not personally totally persuaded that an extreme event attribution service is a good idea" and "it's not obvious to me that an operational attribution service is really what users need." This does not imply that such a service would not meet a need, although the existence of such a need does not appear to have been translated in a demand to these interviewees. It is important to notice that the GFCS definition does not necessarily mean that climate services should systematically come from an explicit user demand, especially since, as pointed out by Street (2016), the demand is "relatively unknown and fragmented at present." This question is related to the issue of evaluation of the effectiveness of climate services which is generally tricky (Tall et al. 2018; Vaughan and Dessai 2014). It also questions the weight one should give to existing studies of the social demand, and how many conclusive or inconclusive results it takes to deem a service valuable for society or not.

Finally, the climate service provider has to identify the kind of users for the service. In the process of involving end-users in the EEA climate service construction, should this service be driven by the restricted ensemble of users who are willing to pay for such a service? Indeed, having users ready to pay for the service is seen by some as a good way to prove that there is a demand for the service. However, this angle raises three issues. First, where is the justification to publicly fund a service that users are willing to pay for? Having users paying for a service already perfectly defined and marketable asks for the reason why public institutions like ERA4CS or C3S should fund them. Second, the restriction of the target to users willing to pay for such a service could also lead to forgetting potential users. These users could for example be users willing to pay in the future, but not fully convinced at the beginning of the project by the product offered (EEA is still in development stages), or not yet aware of the benefits of such services on their activities. Last, there is value in providing public climate services when there is a shared consensus that the service would lead to social benefits but cannot be provided by the market as no individual or private actor has enough incentive to pay for it by its own. EEA is one of the examples of services that can only work (at least in the beginning) as part of the "layer of public, free, open access climate services" recommended by Street (2016).

Another possible answer to which kind of users the service should provide for could be users changing their practices based on the produced results, with EEA as a tool to help them to take decisions. The case of EEA is interesting because it brings to the table a kind of users who could be considered as simply curious about the results without necessarily meaning to consequently change their practices, such as the general public, through the media (and the media themselves). It is up to the service provider to determine whether this type of users is sufficient to justify the cost of building and maintaining a climate service.

The discrepancy we have outlined appears when EEA is evaluated near end users who are exposed to a direct profit or loss, and are not necessarily trained scientists. However, an EEA climate service built for institutions satisfies an explicit demand, which makes it de facto relevant. The effectiveness of this future EEA service and its ability to reach out to other noninstitutional users still needs to be demonstrated. 
Acknowledgments. This work was supported by the ERC Grant 338965-A2C2. We thank three anonymous reviewers for their constructive comments.

\section{REFERENCES}

Adam, D., 2011: Climate change in court. Nat. Climate Change, $\mathbf{1}$ 127-130, https://doi.org/10.1038/nclimate1131.

Allen, M., 2003: Liability for climate change. Nature, 421, 891-892, https://doi.org/10.1038/421891a.

_ , and R. Lord, 2004: The blame game. Nature, 432, 551-552, https://doi.org/10.1038/432551a.

— , P. Pall, D. Stone, P. Stott, D. Frame, S.-K. Min, T. Nozawa, and S. Yukimoto, 2007: Scientific challenges in the attribution of harm to human influence on climate. Univ. Pa. Law Rev., 155, 1353-1400.

Bohr, J., 2017: Is it hot in here or is it just me? Temperature anomalies and political polarization over global warming in the American public. Climatic Change, 142, 271-285, https:// doi.org/10.1007/s10584-017-1934-z.

Boran, I., and J. Heath, 2016: Attributing weather extremes to climate change and the future of adaptation policy. Ethics Policy Environ., 19, 239-255, https://doi.org/10.1080/ 21550085.2016.1226236.

Bray, D., and H. von Storch, 2016: The Bray and von Storch 5th International Survey of Climate Scientists 2015/2016, HZG Report 2016-2, Helmholtz-Zentrum Geesthacht, 129 pp., https:// doi.org/10.13140/RG.2.2.11802.85443.

Christidis, N., P. A. Stott, and F. W. Zwiers, 2015: Fast-track attribution assessments based on pre-computed estimates of changes in the odds of warm extremes. Climate Dyn., 45, 15471564, https://doi.org/10.1007/s00382-014-2408-x.

Dessai, S., and M. Hulme, 2004: Does climate adaptation policy need probabilities? Climate Policy, 4, 107-128, https://doi.org/ 10.1080/14693062.2004.9685515.

,,-- R. Lempert, and R. Pielke Jr., 2009: Climate prediction: A limit to adaptation. Adapting to Climate Change: Thresholds, Values, Governance, W. N. Adger, I. Lorenzoni, and K. L. O'Brien, Eds., Cambridge University Press, 64-78.

Füssel, H.-M., 2007: Adaptation planning for climate change: Concepts, assessment approaches, and key lessons. Sustain. Sci., 2 , 265-275, https://doi.org/10.1007/s11625-007-0032-y.

Grossman, D. A., 2003: Warming up to a not-so-radical idea: Tort-based climate change litigation. Colum. J. Environ. Law, 28, $1-62$.

Hamilton, L. C., C. P. Wake, J. Hartter, T. G. Safford, and A. J. Puchlopek, 2016: Flood realities, perceptions and the depth of divisions on climate. Sociology, 50, 913-933, https://doi.org/ 10.1177/0038038516648547.

Hewitt, C., S. Mason, and D. Walland, 2012: The global framework for climate services. Nat. Climate Change, 2, 831-832, https:// doi.org/10.1038/nclimate1745.

Hoegh-Guldberg, O., G. Hegerl, T. Root, F. Zwiers, P. Stott, D. Pierce, and M. Allen, 2011: Difficult but not impossible. Nat. Climate Change, 1, 72, https://doi.org/10.1038/nclimate1107.

Huggel, C., I. Wallimann-Helmer, D. Stone, and W. Cramer, 2016: Reconciling justice and attribution research to advance climate policy. Nat. Climate Change, 6, 901-908, https://doi.org/ 10.1038/nclimate3104.

Hulme, M., 2014: Attributing weather extremes to 'climate change': A review. Prog. Phys. Geogr. Earth Environ., 38, 499-511, https://doi.org/10.1177/0309133314538644.
_ S. J. O'Neill, and S. Dessai, 2011: Is weather event attribution necessary for adaptation funding? Science, 334, 764-765, https://doi.org/10.1126/science.1211740.

Imada, Y., H. Shiogama, C. Takahashi, M. Watanabe, M. Masato, Y. Kamae, and S. Maeda, 2018: Climate change increased the likelihood of the 2016 heat extremes in Asia [in "Explaining Extreme Events of 2016 from a Climate Perspective"]. Bull. Amer. Meteor. Soc., 99 (1), S97-S101, https://doi.org/10.1175/ BAMS-D-17-0109.1.

James, R., F. Otto, H. Parker, E. Boyd, R. Cornforth, D. Mitchell, and M. Allen, 2014: Characterizing loss and damage from climate change. Nat. Climate Change, 4, 938-939, https://doi.org/ 10.1038/nclimate2411.

- R. G. Jones, E. Boyd, H. R. Young, F. E. L. Otto, C. Huggel, and J. S. Fuglestvedt, 2019: Attribution: How is it relevant for loss and damage policy and practice? Loss and Damage from Climate Change, R. Mechler et al., Eds., Springer, 113-154, https://doi.org/10.1007/978-3-319-72026-5_5.

Jézéquel, A., V. Dépoues, H. Guillemot, M. Trolliet, J.-P. Vanderlinden, and P. Yiou, 2018: Behind the veil of extreme event attribution. Climatic Change, 149, 367-383, https://doi.org/ 10.1007/s10584-018-2252-9.

$\longrightarrow$, P. Yiou, and J.-P. Vanderlinden, 2019: Comparing scientists and delegates perspectives on the use of extreme event attribution for loss and damage. Wea. Climate Extremes, https:// doi.org/10.1016/j.wace.2019.100231, in press.

Knoblauch, T. A. K., M. Stauffacher, and E. Trutnevyte, 2018: Communicating low-probability high-consequence risk, uncertainty and expert confidence: Induced seismicity of deep geothermal energy and shale gas. Risk Anal., 38, 694-709, https://doi.org/10.1111/risa.12872.

Knutson, T. R., J. Kam, F. Zeng, and A. T. Wittenberg, 2018: CMIP5 model-based assessment of anthropogenic influence on record global warmth during 2016 [in "Explaining Extreme Events of 2016 from a Climate Perspective"]. Bull. Amer. Meteor. Soc., 99 (1), S11-S15, https://doi.org/10.1175/BAMS-D-17-0104.1.

Konisky, D. M., L. Hughes, and C. H. Kaylor, 2016: Extreme weather events and climate change concern. Climatic Change, 134, 533-547, https://doi.org/10.1007/s10584-015-1555-3.

Leiserowitz, A., E. Maibach, C. Roser-Renouf, and J. D. Hmielowski, 2012: Extreme weather, climate \& preparedness in the American mind. Yale Project on Climate Change Communication, 20 pp., http://environment.yale.edu/ climate/files/Extreme-Weather-Climate-Preparedness.pdf.

Lloyd, E. A., and N. Oreskes, 2018: Climate change attribution: When is it appropriate to accept new methods? Earth's Future, 6, 311-325, https://doi.org/10.1002/2017EF000665.

Lusk, G., 2017: The social utility of event attribution: Liability, adaptation, and justice-based loss and damage. Climatic Change, 143, 201-212, https://doi.org/10.1007/s10584-017-1967-3.

Mace, M., and R. Verheyen, 2016: Loss, damage and responsibility after COP21: All options open for the Paris agreement. Rev. Eur. Comp. Int. Environ. Law, 25, 197-214, https://doi.org/ 10.1111/reel.12172.

Marjanac, S., and L. Patton, 2018: Extreme weather event attribution science and climate change litigation: An essential step in the causal chain? J. Energy Nat. Resour. Law, 36, 265-298, https://doi.org/10.1080/02646811.2018.1451020.

Marlon, J. R., S. van der Linden, P. D. Howe, A. Leiserowitz, S. H. L. Woo, and K. Broad, 2019: Detecting local environmental change: The role of experience in shaping risk judgments about global warming. J. Risk Res., 22, 936-950, https:// doi.org/10.1080/13669877.2018.1430051. 
Marquart-Pyatt, S. T., A. M. McCright, T. Dietz, and R. E. Dunlap, 2014: Politics eclipses climate extremes for climate change perceptions. Global Environ. Change, 29, 246-257, https:// doi.org/10.1016/j.gloenvcha.2014.10.004.

Massey, N., and Coauthors, 2015: weather@home-Development and validation of a very large ensemble modelling system for probabilistic event attribution. Quart. J. Roy. Meteor. Soc., 141, 1528-1545, https://doi.org/10.1002/qj.2455.

McIvor, C., 2013: Debunking some judicial myths about epidemiology and its relevance to UK tort law. Med. Law Rev., 21, 553-587, https://doi.org/10.1093/medlaw/fwt017.

Moser, S. C., and M. T. Boykoff, 2013: Climate change and adaptation success: The scope of the challenge. Successful Adaptation to Climate Change: Linking Science and Policy in a Rapidly Changing World, Routledge, 25-58.

Nachmany, M., and J. Setzer, 2018: Policy brief global trends in climate change legislation and litigation: 2018 snapshot. Grantham Research Institute on Climate Change and the Environment, 8 pp.

—, S. Fankhauser, J. Setzer, and A. Averchenkova, 2017: Global trends in climate change legislation and litigation: 2017 update. Grantham Research Institute on Climate Change and the Environment, 24 pp., http://www.lse.ac.uk/GranthamInstitute/ publication/global-trends-in-climate-change-legislation-andlitigation-2017-update/.

National Academies of Sciences, Engineering, and Medicine, 2016: Attribution of Extreme Weather Events in the Context of Climate Change. The National Academies Press, 186 pp., https:// doi.org/10.17226/21852.

Otto, F. E., 2017: Attribution of weather and climate events. Annu. Rev. Environ. Resour., 42, 627-646, https://doi.org/10.1146/ annurev-environ-102016-060847.

Pall, P., T. Aina, D. A. Stone, P. A. Stott, T. Nozawa, A. G. J. Hilberts, D. Lohmann, and M. R. Allen, 2011: Anthropogenic greenhouse gas contribution to flood risk in England and Wales in autumn 2000. Nature, 470, 382-385, https://doi.org/ 10.1038/nature09762.

Parker, H. R., E. Boyd, R. J. Cornforth, R. James, F. E. L. Otto, and M. R. Allen, 2017: Stakeholder perceptions of event attribution in the loss and damage debate. Climate Policy, 17, 533550, https://doi.org/10.1080/14693062.2015.1124750.

Phelan, L., 2011: Managing climate risk: Extreme weather events and the future of insurance in a climate-changed world. Australas. J. Environ. Manage., 18, 223-232, https://doi.org/ 10.1080/14486563.2011.611486.

Reguly, E., 2013: No climate-change deniers to be found in the reinsurance business. Globe and Mail, 28 November 2013, https:/www.theglobeandmail.com/report-on-business/robmagazine/an-industry-that-has-woken-up-to-climate-changeno-deniers-at-global-resinsurance-giant/article15635331/.

Roberts, E., and M. Pelling, 2018: Climate change-related loss and damage: Translating the global policy agenda for national policy processes. Climate Dev., 10, 4-17, https://doi.org/ 10.1080/17565529.2016.1184608.

Rudiak-Gould, P., 2013: "We have seen it with our own eyes": Why we disagree about climate change visibility. Wea. Climate Soc., 5, 120-132, https://doi.org/10.1175/WCAS-D-12-00034.1.

Schacter, D. L., D. R. Addis, and R. L. Buckner, 2007: Remembering the past to imagine the future: The prospective brain. Nat. Rev. Neurosci., 8, 657-661, https://doi.org/10.1038/nrn2213.

Schwab, M., I. Meinke, J.-P. Vanderlinden, and H. von Storch, 2017: Regional decision-makers as potential users of extreme weather event attribution-Case studies from the German
Baltic Sea coast and the Greater Paris area. Wea. Climate Extremes, 18, 1-7, https://doi.org/10.1016/j.wace.2017.09.001.

Shepherd, T. G., 2016: A common framework for approaches to extreme event attribution. Curr. Climate Change Rep., 2, 28-38, https://doi.org/10.1007/s40641-016-0033-y.

_ 2019: Storyline approach to the construction of regional climate change information. Proc. Roy. Soc., 475A, 20190013 , https://doi.org/10.1098/rspa.2019.0013.

_ _ and Coauthors, 2018: Storylines: An alternative approach to representing uncertainty in physical aspects of climate change. Climatic Change, 151, 555-571, https://doi.org/10.1007/s10584-018-2317-9.

Sillmann, J., S. Russo, S. Sippel, and K. Alnes, 2018: From hazard to risk. Bull. Amer. Meteor. Soc., 99, 1689-1693, https://doi.org/ 10.1175/BAMS-D-17-0327.1

Sippel, S., P. Walton, and F. E. L. Otto, 2015: Stakeholder perspectives on the attribution of extreme weather events: An explorative enquiry. Wea. Climate Soc., 7, 224-237, https:// doi.org/10.1175/WCAS-D-14-00045.1.

Stott, P. A., and P. Walton, 2013: Attribution of climate-related events: Understanding stakeholder needs. Weather, 68, 274 279, https://doi.org/10.1002/wea.2141.

_ D. A. Stone, and M. R. Allen, 2004: Human contribution to the European heatwave of 2003. Nature, 432, 610-614, https:// doi.org/10.1038/nature03089.

—, M. Allen, N. Christidis, R. M. Dole, M. Hoerling, C. Huntingford, P. Pall, J. Perlwitz, and D. Stone, 2013: Attribution of weather and climate-related events. Climate Science for Serving Society, G. R. Asrar and J. W. Hurrell, Eds., Springer, 307-337, https://doi.org/10.1007/978-94-007-6692-1_12.

_ , and Coauthors, 2016: Attribution of extreme weather and climate-related events. Wiley Interdiscip. Rev.: Climate Change, 7, 23-41, https://doi.org/10.1002/wcc.380.

Street, R. B., 2016: Towards a leading role on climate services in Europe: A research and innovation roadmap. Climate Serv., 1, 2-5, 2016, https://doi.org/10.1016/j.cliser.2015.12.001.

Surminski, S., and A. Lopez, 2015: Concept of loss and damage of climate change-A new challenge for climate decisionmaking? A climate science perspective. Climate Dev., 7, 267-277, https://doi.org/10.1080/17565529.2014.934770.

Tall, A., J. Y. Coulibaly, and M. Diop, 2018: Do climate services make a difference? A review of evaluation methodologies and practices to assess the value of climate information services for farmers: Implications for Africa. Climate Serv., 11, 1-12, https://doi.org/10.1016/j.cliser.2018.06.001.

Thompson, A., and F. E. L. Otto, 2015: Ethical and normative implications of weather event attribution for policy discussions concerning loss and damage. Climatic Change, 133, 439-451, https://doi.org/10.1007/s10584-015-1433-z.

Thornton, J., and H. Covington, 2016: Climate change before the court. Nat. Geosci., 9, 3-5, https://doi.org/10.1038/ngeo2612.

Torre-Schaub, M., 2018: Les dynamiques du contentieux climatique, anatomie d'un phénomène émergent. Quel $(s)$ droit $(s)$ pour les changements climatiques? M. Torre-Schaub et al., Eds., Mare et Martin, 111-137.

Travis, W. R., 2014: Weather and climate extremes: Pacemakers of adaptation? Wea. Climate Extremes, 5-6, 29-39, https:// doi.org/10.1016/j.wace.2014.08.001.

Trenberth, K. E., J. T. Fasullo, and T. G. Shepherd, 2015: Attribution of climate extreme events. Nat. Climate Change, 5, 725730, https://doi.org/10.1038/nclimate2657.

Vanderlinden, J.-P., M. Schwab, I. Meinke, T. Lescuyer, H. H. Rabearisoa, S. Bila, and N. Touili, 2016: Eucleia deliverable d4.4: Empirical working paper: Perceiving attribution, 90 pp. 
Vaughan, C., and S. Dessai, 2014: Climate services for society: Origins, institutional arrangements, and design elements for an evaluation framework. Wiley Interdiscip. Rev.: Climate Change, 5, 587-603, https://doi.org/10.1002/wcc.290.

Verchick, R. R. M., 2018: Can 'loss and damage' carry the load? Philos. Trans. Roy. Soc., 376A, 20170070, https://doi.org/ 10.1098/rsta.2017.0070.

von Storch, H., M. Schwab, I. Meinke, J.-P. Vanderlinden, and N. Touili, 2015: Eucleia deliverable d4.2: Empirical working paper: Analysing stakeholders' needs and understanding, $57 \mathrm{pp}$. $-,-\longrightarrow,-$, and,- 2016 : Eucleia deliverable d4.3: Empirical working paper: Commercial dimension of attribution products, $50 \mathrm{pp}$.

Wallimann-Helmer, I., 2015: Justice for climate loss and damage. Climatic Change, 133, 469-480, https://doi.org/10.1007/s10584015-1483-2.
Walsh, J. E., and Coauthors, 2018: The high latitude marine heatwave of 2016 and its impacts on Alaska [in "Explaining Extreme Events of 2016 from a Climate Perspective"]. Bull. Amer. Meteor. Soc., 99 (1), S39-S43, https://doi.org/10.1175/ BAMS-D-17-0105.1.

Warner, K., K. Yuzva, M. Zissener, S. Gille, J. Voss, and S. Wanczeck, 2013: Innovative insurance solutions for climate change: How to integrate climate risk insurance into a comprehensive climate risk management approach. United Nations University Institute for Environment and Human Security (UNU-EHS), Rep. 12, 51 pp.

Weaver, C. P., R. J. Lempert, C. Brown, J. A. Hall, D. Revell, and D. Sarewitz, 2013: Improving the contribution of climate model information to decision making: The value and demands of robust decision frameworks. Wiley Interdiscip. Rev.: Climate Change, 4, 39-60, https://doi.org/10.1002/wcc.202. 